David Javid, Kris Krasnove MCRP Students

Vicente del Rio, Daniel Levi

Professors

City and Regional Planning Department

Environmential Psychology Department

Cal Poly San Luis Obispo
Sense of Community and Travel Behavior: Investigating New Urbanism and Smart Growth Principles in Two Residential Neighborhoods in San Luis Obispo County.

This paper was first presented in poster format at the 2004 annual conference of the Association of Collegiate Schools of Planning in Portland. It comments on the results of research conducted by the authors with the support of a Community Development Grant from Cal Poly's CAED and the Orfalea College of Business.

New Urbanism and Smart Growth are relatively new approaches to city planning and urban design that are designed to deal with the environmental problems, housing issues, and community well-being. The central principles of Smart Growth are that land uses should be mixed and higher densities and multi-family housing should be encouraged. New Urbanism includes the principles of Smart Growth, but adds that development should be visually tied together by the use of prescribed historic styles of architecture.

Advocates of Smart Growth and New Urbanism make a number of claims about the value of this approach to planning. By encouraging mixed land-use and higher densities, urban sprawl should be reduced, which encourages sustainable development. Because people will be able to live near where they work, shop, and find entertainment, Smart Growth strategies should encourage walking and bicycle use, use of public transportation, and reduced use of automobiles. Because people will be living closer together and interact more with neighbors on the street and in commercial areas, Smart Growth should also encourage a heightened sense of community. New Urbanism advocates the use of consistent design themes, especially the use of historic design styles, to encourage increased sense of community due to stronger identification with one's local environment.

\section{THE RESEACH}

Although there has been research on the social and psychological impacts of Smart Growth and New Urbanism, this research has primarily focused on new developments that were designed based on these principles. There is a problem with such research approach, because new residential developments tend to attract people with similar characteristics that are related to the development's marketing approach. Consequently, it is difficult to tell whether New Urbanist communities encourage a sense of identity, or whether an increased sense of identity is caused by higher level of social homogeneity. Also, do people walk more in New Urbanist communities because of higher densities and mixed-uses, or because New Urbanist communities attract environmentally-oriented people who walk and ride bikes more.

The main goal of the investigation reported here was to examine two of the main social and environmental impacts of New Urbanism/Smart Growth. These impacts are a) increased sense of community, and b) increased walking, biking, and use of public transportation (and reduced automobile use). Rather than trying to study new developments that have been designed and marketed as New Urbanism communities, our study used the Smart Growth and New Urbanism principles to identify existing developments that although not designed "New Urbanist" meet these criteria. This will allow a comparison study to determine whether designs using these planning principles create the hypothesized social and psychological effects of New Urbanism and Smart Growth.

Therefore, the focus of our study was to examine the potential impacts of urban form on travel behavior and sense of community. For travel behavior, the goal was to determine if neighborhood design features promoted by New Urbanism influence mode of transportation choices, by encouraging more walking and fewer automobile trips. For sense of community the goal of the research was to determine the type of influence New Urbanism design principles have on neighboring activities and sense of place within the study areas. Based on the methods and earlier findings of Talen (1999), Lund (2002, 2003), and Keith (2003), we studied residents' attitudes toward sense of community and travel behavior in two local neighborhoods. These two case studies were the Village of Arroyo Grande and the Laguna Lake Neighborhood in the City of San Luis Obispo, CA. Both these areas reflect New Urbanist qualities as they 
both contain dense residential neighborhoods that are within walking distance of schools, commercial, civic, and recreational uses.

This research, although social in nature, is a quantified approach to answering the questions posed by the New Urbanism critics. How can neighborhood design influence travel behavior, and how is community established through the presence of civic spaces and pedestrian-orientation?

\section{EVALUATION CRITERIA AND DATA GATHERING}

The evaluation method allowed consideration of which New Urbanism criteria the neighborhoods were lacking. Because New Urbanism criteria were being utilized to evaluate local neighborhoods, a mechanism was needed to measure the neighborhoods against each other. The 13 principles developed by Duany and Plater-Zyberk provided a comprehensive inventory of the planning concept's community design standards.

The features of the Village and Laguna Lake were tested against the "Traditional Neighborhood Development" criteria, and were awarded a numeric score between 3 (High), 2 (Medium), and 1 (Low). The criteria were broken down into two categories: 1. Neighborhood Amenities and 2. Design Features. The Neighborhood Amenities category consisted of criteria requiring a combination of uses within $1 / 4$ mile of residences and the existence of a town center. The Design Features category included street design and reduced setbacks to ensure pedestrian orientation. The two neighborhoods scored equally on Neighborhood Amenities, but the Village scored higher in the Design Features category. The scores show that both neighborhoods have facilities for a combination of uses, but the Village has greater New Urbanism design features than Laguna Lake.

Basic information about the two study areas, such as demographic and housing tenure data, was obtained from the U.S. Census Bureau. A survey questionnaire was used to gather data about residents' attitudes toward neighborhood design characteristics and its impact on sense of community and travel behavior. Similar to the one employed by Keith (2003), the survey was based on past studies which used specific indicators to evaluate sense of community and travel behavior. Surveys were distributed following a random sampling process, delivered door-to-door and attached to door knobs in the study areas. The return rate from both communities was $35 \%$ or greater.

\section{CONCLUSIONS}

The GIS data indicate that Village of Arroyo Grande and the Laguna Lake Neighborhood both meet the neighborhood design qualities that the two urban design movements advocate; however, the Village of Arroyo Grande meets more of those criteria. Our survey results suggest that residents of the neighborhood containing more New Urbanism principles, the Village of Arroyo Grande, experience superior sense of community, as they know more of their neighbors and participate in neighboring activities more often than Laguna Lake Neighborhood residents. Its greater overall sense of community was attributed to neighboring indicators, but the reason why residents were acquainted with more of their neighbors was surprisingly not attributed to the pedestrian activity.

Findings indicate that in both neighborhoods pedestrian activity is low and the automobile is the most used mode of transportation. Considering the relatively short distance between the homes and a variety of uses in both neighborhoods, New Urbanists might have predicted that the drive-alone trips would be more moderate. Although the two neighborhoods meet New Urbanism guidelines by providing a variety of uses within $1 / 4$ to $1 / 2$ mile of each other, the lack of pedestrian activity may be attributed to limited pedestrian facilities and connectivity, and the lack of adequate links between the residential uses and commercial and recreational areas. In addition, the inability to control demographics in the study areas makes it difficult to conclude that design features and not housing tenure, length of residency, and median age have combined to influence the sense of community results.

The form of the built environment does not seem to cause a direct impact on the way inhabitants travel within their neighborhoods. However, residents within the study areas reported that essential pedestrian-oriented amenities are lacking, which may influence their travel behavior. No significant difference in automobile dependency exists between the two neighborhoods.

Residents in the Laguna Lake Neighborhood do not find it important to live near schools, although there is an elementary school centrally located in their community and two other 
schools on its periphery. The college students living in the area may have influenced this outcome as many of them drive to school. Consequently, the results from the survey suggest that in both neighborhoods, an automobile was used for the majority of school trips.

Although the majority of residents elect to drive alone, residents in the Laguna Lake Neighborhood reported that the most common destination for walking trips was to go grocery shopping. That is not surprising considering the location of the Laguna Lake Shopping Center, but again the potential for walking trips could be greater if the areas had better physical connections for easy pedestrian use.

Residents in both neighborhoods also chose to walk to visit family and friends and for leisure and recreation. Handy and Clifton (2001) found that trips for leisure or "strolling trips" are a good indication of the comfort level residents have within their community as pedestrian-friendly streetscapes generally encourage more walking trips. Therefore, pedestrian amenities such as the wide sidewalks in the Laguna Lake Neighborhood may have influenced some of the walking trips.

A test of the walk variable as an indicator of the impact of the neighborhood design features on travel behavior, specifically pedestrian activity, produced results that would generally support the claims of New Urbanism. In both neighborhoods, it is apparent that those residents that walk to local destinations also value living in close proximity to the grocery store and community parks and open space.

The amenities available in the Village of Arroyo Grande and the Laguna Lake Neighborhood, afforded residents the opportunity to choose to walk to some of their destinations. Similarly, those who walked more also reported that the location of parks and sense of community are important factors in their decision to locate to a particular neighborhood. This suggests that those who rely more on active modes of transportation are likely to interact with their neighbors and feel a part of their community. In addition, this result can be an indication of self-selection, where respondents may have chosen to move to these areas due to the availability of pedestrian-oriented amenities and existing community cohesion.

There are many factors that may have influenced the results of the survey, which include personal preference and behavioral characteristics of residents that are not impacted by neighborhood design. Overall, the findings from an evaluation of two study areas did not show a significant relationship between the layout of the built environment and the way people travel through it. Although the study found that a greater sense of community was experienced by residents of the more "New Urbanist" neighborhood, it was not established which of the design features produced the results. Suburban neighborhood design features like those present in both the Laguna Lake Neighborhood and the Village of Arroyo Grande include wide automobile-oriented streets that may be the contributing factor to the lack of pedestrian activity in those communities.

The assumption that compact neighborhood form that places a mix of uses within close proximity will induce pedestrian activity, and therefore a greater sense of community, did not hold true in this study. There was no relationship found between pedestrian behavior and attitude towards community. As alluded to above, walking trips may be influenced by the lack of essential pedestrian access and connectivity in the Laguna Lake Neighborhood, even though the streetscape is generally pedestrian-oriented.

Adequate walkable links to shops and services are present in the Village of Arroyo Grande, however the combination of wide streets and disjointed sidewalks in the residential neighborhood may impact the residents' transportation choices. In addition, residents in both study areas expressed concern about the size of the streets in their neighborhoods, noting that the streets are designed to accommodate automobile traffic and that speeding has consequently become an issue.

Our findings suggest that the urban design model that Smart Growth and New Urbanism are based on may not produce their intended results in every setting. Keith's (2003) study generated similar results, suggesting that specific New Urbanist neighborhood design features may not directly impact travel behavior or sense of community. Therefore, the urban design concept is criticized as being inadequate or flawed.

However, as an implementation tool of Smart Growth principles, New Urbanism should be viewed as a strategy that can not stand alone but if integrated effectively through programs such as efficient infill and planned 
development efforts, can enhance pedestrian activity and promote social interaction. Although urban design practices may not alter human behavior, they provide the opportunity for choice, which is often lacking in typical suburban automobile-oriented design.

\section{REFERENCES}

Lund, H. (2003). Testing the Claims of New Urbanism. American Planning Association Journal, vol. 26 \# 4: 414-429.

(2002). Pedestrian Environments and Sense of Community. Journal of Planning Education and Research, vol. 21: 301-312.

Keith, T. (2003). New Urbanism, Sense of Community, and Automobile Dependence: A Comparative Study of Two Residential Developments in California. MCRP Thesis. California Polytechnic State University, San Luis Obispo.

Talen, E. (2002). The Social Goals of New Urbanism. Housing Policy Debate, vol. 13 \# 1, Fannie Mae Foundation: 165-188. 